\title{
Prevalence study and risk factor analysis of selected bacterial, protozoal and viral, including vector-borne, pathogens in cats from Cyprus
}

Charalampos Attipa ${ }^{1,2^{*}}$ D, Kostas Papasouliotis ${ }^{1}$, Laia Solano-Gallego ${ }^{3}$, Gad Baneth ${ }^{4}$, Yaarit Nachum-Biala ${ }^{4}$, Elpida Sarvani ${ }^{1}$, Toby G. Knowles ${ }^{5}$, Sena Mengi ${ }^{6}$, David Morris ${ }^{1}$, Chris Helps ${ }^{1}$ and Séverine Tasker ${ }^{1,5}$

\begin{abstract}
Background: Feline infectious agent studies are lacking in Cyprus. The aims of this study were to determine the prevalence and risk factors for various feline infectious agents, including feline vector-borne pathogens (FVBP), in cats from Cyprus.

Methods: A cross-sectional, descriptive, multicentre study was performed on 174 feline samples [138 owned and 36 shelter-feral, including both healthy (43) and non-healthy (131), cats] from private veterinary clinics from all six districts of Cyprus. Real-time quantitative polymerase chain reaction (qPCR) assays were used to detect Mycoplasma haemofelis (Mhf), "Candidatus Mycoplasma haemominutum" (CMhm) and "Candidatus Mycoplasma turicensis" (CMt). The population was tested for four FVBP including Bartonella henselae and Leishmania spp. using qPCR, while conventional PCR assays were used to detect Ehrlichia/Anaplasma spp. and Hepatozoon spp. Serological assays were performed to detect Leishmania infantum antibodies, feline leukaemia virus (FeLV) antigen and feline immunodeficiency virus (FIV) antibodies. Statistical analysis was performed to test associations and possible risk factors between variables and infectious agents.

Results: Ninety-six (55.2\%) of the 174 cats were PCR-positive for at least one infectious agent. Forty-six cats (26.4\%) were haemoplasma positive, including 13 (7.5\%) for Mhf, 36 (20.7\%) for CMhm and 12 (6.9\%) for CMt. Sixty-six cats (37.9\%) were positive for Hepatozoon spp., while 19 (10.9\%) were positive for B. henselae, four (2.3\%) for Leishmania spp. and one (0.6\%) for Ehrlichia/Anaplasma spp. Sequencing revealed the presence of Hepatozoon felis, L. infantum and Anaplasma platys. Of the 164 cats that underwent retroviral serology, 10 (6.1\%) were FeLV-positive and 31 (18.9\%) were FIV-positive, while L. infantum serology was positive in 7 (4.4\%) of the 160 cats tested. Multivariable logistic regression revealed significant associations for various infectious agents including L. infantum with each of Hepatozoon spp. and CMt infection.

Conclusions: A high prevalence of infectious agents was found in cats from Cyprus with Mhf, CMhm, CMt, L. infantum, B. henselae, H. felis, A. platys, FeLV and FIV infections reported for the first time. The significant associations between different pathogens provide a better understanding of similarities in the epidemiology of these pathogens and interactions between them.
\end{abstract}

Keywords: Cyprus, Feline vector-borne pathogens, Leishmania infantum, Bartonella henselae, Anaplasma platys, Hepatozoon felis, Haemoplasma, FeLV, FIV

\footnotetext{
* Correspondence: attipacy@gmail.com

${ }^{1}$ Molecular Diagnostic Unit, Diagnostic Laboratories, Langford Vets and School

of Veterinary Sciences, University of Bristol, Langford, UK

${ }^{2}$ Cyvets Veterinary Center, Paphos, Cyprus

Full list of author information is available at the end of the article
} 


\section{Background}

The Republic of Cyprus is an island state located at the crossroads between Europe, Asia and Africa, with the first evidence of cat domestication reported 9,500 years ago [1]. It is the third largest Mediterranean island with a territory of $9,251 \mathrm{~km}^{2}$ of which almost half is dominated by mountain ranges. The climate of Cyprus is warmer than the temperate climate typical of some other European Mediterranean countries. This, combined with the geographical location and other factors, favours the maintenance of many arthropod vectors including ticks, fleas, phlebotomine sand flies and mosquitoes [2-6].

While many studies on feline haemoplasmas, feline leukaemia virus (FeLV) and feline immunodeficiency virus (FIV) have been performed worldwide, feline vector-borne pathogens (FVBP) have only been studied relatively recently, and are showing an expanding distribution [7-16]. This illustrates the potential cats have for maintaining and distributing vector-borne pathogens (VBP), some of which are zoonotic.

Vector-borne pathogens have been identified in the government-controlled southern part of Cyprus in various host animal species; Leishmania infantum, Ehrlichia canis, Anaplasma platys, Hepatozoon canis, Babesia vogeli and Mycoplasma haemocanis have been reported in dogs [6, 17], and several rickettsial agents have been reported in goats, sheep, cattle, dogs, mouflon, foxes and hares $[2,3]$. Until now, no epidemiological studies have been performed for any infectious agent in cats from Cyprus nor in any small animal species from the nongovernment-controlled northern part of the country.

The aims of this study were to investigate the presence of several infectious agents, including some FVBP with zoonotic concern, in cats from the whole of Cyprus and to identify risk factors associated with them using multivariable logistic regression. Specifically, we investigated feline haemoplasmas [Mycoplasma haemofelis (Mhf), "Candidatus Mycoplasma haemominutum" (CMhm) and "Candidatus Mycoplasma turicensis" (CMt)], Bartonella henselae, Hepatozoon spp., Leishmania spp. and Ehrlichia/Anaplasma spp. using DNA-based detection techniques. Additionally, specific antibodies for FIV and Leishmania infantum antigens were determined and antigenaemia was assessed for FeLV.

\section{Methods}

\section{Animals and samples}

From March to September 2014, a total of 176 cats from veterinary clinics in Cyprus were studied. Cats were from urban and rural areas of all six districts of the island; Paphos, Nicosia, Larnaca, Limassol, Famagusta and Kyrenia. Surplus EDTA-blood $(0.5-1.0 \mathrm{ml})$, and when possible serum $(0.5-1.0 \mathrm{ml})$, were collected from cats following written consent from the cat owner or person in charge of the animal shelter. The healthy cat samples comprised pre-anaesthetic screens or samples collected for check-ups (e.g. pre- or post-traveling) whilst the samples from clinically ill animals were taken for diagnostic investigations.

Samples were stored at $-20{ }^{\circ} \mathrm{C}$ until transported on dry ice to the Diagnostic Laboratories, Langford Vets, University of Bristol, UK, for testing. Data on age, gender (male or female), breed (non-pedigree or pedigree), housing (access to outdoors or indoors only), lifestyle (shelter-feral or owned), district of cat origin in Cyprus (Paphos, Nicosia, Larnaca, Limassol, Famagusta or Kyrenia), habitat (rural or urban), any previous travel history abroad (never travelled abroad or travelled abroad) and health status (non-healthy or healthy, determined by the veterinarian) were registered for each cat. Whenever available, data on the cat's vaccination status (never vaccinated or vaccinated), use of ectoparasitic prevention (never used or used) and presence of anaemia (haematocrit $<25 \%$ ), based on in-house complete blood count, were also recorded.

\section{Polymerase chain reaction (PCR) tests}

The DNA was extracted from $100 \mu \mathrm{l}$ of EDTA blood using a commercial kit (Macherey-Nagel nucleospin blood kit, Düren, Germany) according to the manufacturer's instructions. During extraction nuclease-free water was used as a negative extraction control. The DNA was eluted with $100 \mu$ l of elution buffer provided with the kit and stored at $-20{ }^{\circ} \mathrm{C}$ prior to analysis.

In order to assess the presence of amplifiable DNA, the absence of PCR inhibitors and correct assay setup, all quantitative (q) PCRs were duplexed with an internal amplification control. For the haemoplasma qPCRs, the feline 28S rRNA gene was used and a threshold cycle $(\mathrm{Ct})$ cut-off value of $<30$ was used to indicate adequate amplifiable DNA. For the Leishmania spp. and B. henselae qPCRs, the glyceraldehyde-3-phosphate dehydrogenase gene was used and a Ct value of $<27$ was used as a cut-off. Any samples with $\mathrm{Ct}$ values greater than or equal to the cut-off values were excluded from the study due to insufficient quantity/quality of DNA. Multiplex qPCR assays, as previously described, were used to detect infection with Mhf, CMhm, CMt [18], Leishmania spp. (screening assay) [19] and B. henselae [20], and a conventional PCR, as previously described, was used to detect infection with Ehrlichia/Anaplasma spp. [21]. Table 1 lists all the primer sequences and products sizes for the PCR assays used. A novel PCR assay was designed and validated (see below) for the detection of Hepatozoon spp. For each assay, DNA from known infected cats (or dogs for Ehrlichia/Anaplasma spp., Hepatozoon spp. and Leishmania spp.) and nuclease-free water were used as positive and negative controls, respectively. 
Table 1 Polymerase chain reaction details for the $\mathrm{gPCR} / P C R$ assays used in the study for the testing of infectious agents

\begin{tabular}{|c|c|c|c|}
\hline Target species (target gene) & PCR primer or probe sequences $\left(5^{\prime}-3^{\prime}\right)$ & Product size (bp) & Reference \\
\hline \multirow[t]{3}{*}{ Bartonella henselae (alr-gcvP intergenic spacer) } & F: GAGGGAAATGACTCTCTCAGTAAAA & \multirow[t]{3}{*}{110} & \multirow[t]{3}{*}[20]{$^{a}$} \\
\hline & R: TGAACAGGATGTGGAAGAAGG & & \\
\hline & FAM-CAGCCAAATATACGGGCTATCCATCAA-TAMRA & & \\
\hline \multirow[t]{3}{*}{ "Candidatus Mycoplasma haemominutum" (16S rRNA gene) } & F: TGATCTATTGTKAAAGGCACTTGCT & \multirow[t]{3}{*}{135} & \multirow[t]{3}{*}{ [18] } \\
\hline & R: TTAGCCTCYGGTGTTCCTCAA & & \\
\hline & FAM-TTCAATGTGTAGCGGTGGAATGCGT-BHQ1 & & \\
\hline \multirow[t]{3}{*}{ "Candidatus Mycoplasma turicensis" (16S rRNA gene) } & F: AGAGGCGAAGGCGAAAACT & \multirow[t]{3}{*}{138} & \multirow[t]{3}{*}{ [18] } \\
\hline & R: ACGTAAGCTACAACGCCGAAA & & \\
\hline & FAM-CGTAAACGATGGGTATTAGATGTCGGGAT-BHQ1 & & \\
\hline \multirow[t]{2}{*}{ Ehrlichia/Anaplasma spp. (16S rRNA gene) } & F: GGTACCYACAGAAGAAGTCC & \multirow[t]{2}{*}{345} & \multirow[t]{4}{*}[21]{} \\
\hline & R: TAGCACTCATCGTTTACAGC & & \\
\hline \multirow[t]{2}{*}{ Hepatozoon. spp. (18S rRNA gene) } & F: AAACGGCTACCACATNTAAGGA & \multirow[t]{2}{*}{522} & \\
\hline & R: AATACAAATGCCCCCAACTNT & & \\
\hline \multirow[t]{3}{*}{ Leishmania spp. (screening assay) (kinetoplast DNA, kDNA) } & F: CGGGTAGGGGCGTTCTG & \multirow[t]{3}{*}{115} & \multirow[t]{3}{*}{ [19] } \\
\hline & R: ATTTTACACCAACCCCCAGTT & & \\
\hline & FAM-TGGGTGCAGAAATCCCGTTCA-BHQ1 & & \\
\hline \multirow[t]{2}{*}{ Leishmania spp. (confirmatory assay) (kDNA) } & F: CCTATTTAACACCAACCCCCAGT & \multirow[t]{2}{*}{120} & \multirow[t]{2}{*}[22,23]{} \\
\hline & R: GGGTAGGGGCGTTCTGCGAAA & & \\
\hline \multirow[t]{3}{*}{ Mycoplasma haemofelis (16S rRNA gene) } & F: GTGCTACAATGGCGAACACA & \multirow[t]{3}{*}{80} & \multirow[t]{3}{*}{ [18] } \\
\hline & R: TCCTATCCGAACTGAGACGAA & & \\
\hline & FAM-TGTGTTGCAAACCAGCGATGGT-BHQ1 & & \\
\hline
\end{tabular}

Abbreviations: $F$ forward primer sequence, $R$ reverse primer sequence, $F A M$ 6-carboxyfluorescein on the Taqman probe, $B H Q 1$ black hole quencher 1 on the Taqman probe, TAMRA Carboxytetramethylrhodamine on the Taqman probe

${ }^{a}$ The reverse and probe sequences in the original paper are incorrectly labelled; the correct sequences are cited in this table

The DNA from six samples that yielded positive results with the screening Leishmania spp. qPCR assay were shipped to the Koret School of Veterinary Medicine, Hebrew University, Rehovot, Israel for confirmatory Leishmania spp. qPCR analysis, using a previously described assay [22, 23].

\section{Novel Hepatozoon spp. PCR assay}

The PCR assay for Hepatozoon spp. was based on the $18 \mathrm{~S}$ rRNA gene. All available sequences larger than 1,000 bp for Hepatozoon felis, H. canis and Hepatozoon americanum were downloaded from GenBank (https:// www.ncbi.nlm.nih.gov/genbank/) and aligned using CLC Sequence Viewer 6.7.1. The $100 \%$ consensus sequence was used with Primer3 (http://bioinfo.ut.ee/primer30.4.0/primer3) to design primers and MFold (http://una fold.rna.albany.edu/?q=mfold) was used to predict likely secondary structures within the amplicon. The primers, Hep for (5'-AAA CGG CTA CCA CAT NTA AGG A-3') and Hep rev (5'-AAT ACA AAT GCC CCC AAC TNT-3') were chosen, amplifying a PCR product of 504 bp for $H$. canis and $H$. felis and 522 bp for $H$. americanum. Primers were synthesised by Metabion International (Steinkirchen, Germany).
Amplification was performed in a PeqStar 2X thermocycler (Peqlab, Erlangen Germany). A final volume of $25 \mu \mathrm{l}$, containing $12.5 \mu \mathrm{l}$ of $2 \times$ GoTaq G2 Master Mix (Promega, Madison, USA), $7 \mu$ l of nuclease-free water, $0.5 \mu \mathrm{l}$ of forward and reverse primer mix at $10 \mu \mathrm{M}$ each and $5 \mu \mathrm{l}$ of DNA template, was used. Thermocycler conditions were set at $95^{\circ} \mathrm{C}$ for $2 \mathrm{~min}$, followed by 40 cycles of $95{ }^{\circ} \mathrm{C}$ for $15 \mathrm{~s}$ and $60{ }^{\circ} \mathrm{C}$ for $45 \mathrm{~s}$. The DNA of a dog and a cat previously diagnosed with $H$. canis and $H$. felis, respectively, based on positive Hepatozoon spp. PCR [24] and 18S rRNA gene sequencing, were used as positive controls. Nuclease-free water was used as a negative control. All amplicons were run on a $2 \%$ agarose gel (Appleton Woods, Birmingham, UK), using 1X TAE buffer (Thermo Fisher Scientific, Paisley, UK) and ethidium bromide (Sigma-Aldrich, St. Louis, USA) at a final concentration of $50 \mathrm{ng} / \mathrm{ml}$ of gel, at $100 \mathrm{~V}$ for $40 \mathrm{~min}$ and an image of the gel was captured under ultraviolet light.

Specificity was evaluated using samples known to contain H. felis, H. canis, B. canis, Babesia rossi, E. canis, Anaplasma phagocytophilum, L. infantum, Bartonella clarridgeiae, Mhf, CMhm, CMt, M. haemocanis, "Candidatus M. haematoparvum", Neospora caninum and Toxoplasma gondii DNA. Any amplicon produced 
during the validation was purified using the NucleoSpin PCR and Gel Clean-up kit (Macherey-Nagel, Düren, Germany) according to the manufacturer's instructions, quantified with a Qubit ${ }^{\mathrm{Tm}}$ fluorometer (Thermo Fisher Scientific, Paisley, UK) and submitted for DNA sequencing at DNA Sequencing and Services (College of Life Sciences, University of Dundee, Scotland), in both directions using the same primers as those used for the PCR.

\section{DNA sequencing}

Fourteen of the 66 Hepatozoon spp. positive samples (due to financial constraints) from cats living in all 6 districts of Cyprus, and the Ehrlichia/Anaplasma spp. positive sample were purified, quantified and submitted for DNA sequencing as described above. All amplicons from the confirmatory Leishmania spp. qPCR were also sequenced using the BigDye Terminator v3.1 Cycle Sequencing Kit and an ABI PRISM 3100 Genetic Analyzer (Applied Biosystems, Foster city, USA), at the Center for Genomic Technologies, Hebrew University of Jerusalem, Israel. Forward and reverse DNA sequences were assembled, constructed into consensus sequences and aligned for identification of infecting species according to the closest NCBI BLAST (www.ncbi.nlm.nih.gov/BLAST) [25] match against previously deposited GenBank sequences. Hepatozoon spp. (KY215805-KY215818) and Ehrlichia/Anaplasma spp. (KY212527) sequences derived from this study were deposited in the GenBank database. The sequences from the confirmatory Leishmania spp. qPCR were not deposited in GenBank since these species have already been described in dogs from Cyprus [6].

\section{FeLV and FIV serology}

The PetCheck FeLV Antigen Test and PetCheck FIV Antibody Test (IDEXX Laboratories, Westbrook, Maine, USA) were used for the detection of FeLV antigens and antibodies against FIV in the 164 available cat sera samples, respectively, following the manufacturer's instructions.

\section{Leishmania infantum serology}

Available cat sera from 160 cases were shipped to the Departament de Medicina i Cirurgia Animal, Facultat de Veterinaria, Universitat Autonoma de Barcelona, Spain for L. infantum enzyme-linked immunosorbent assay (ELISA) testing using a previously described protocol [26]. A cut-off was established at 32 ELISA units for IgG (mean \pm 3 standard deviations). Each sample was quantified as ELISA units (EU) relative to a positive control calibrator cat serum sample, arbitrarily set at $100 \mathrm{EU}$, which was included on each plate. A negative control cat serum, from a cat known not to be Leishmania-infected, was also included on each plate.

\section{Statistical analysis}

Only samples that were positive for both qPCR internal controls using the stipulated Ct cut-offs were included in the statistical analysis carried out using SPSS for Windows (version 22.0; SPSS Inc., Chicago IL, USA).

For statistical analysis, four groups of infectious agents were formed comprising "Any haemoplasma" (positivity in at least one of the following qPCRs; Mhf, CMhm and CMt), "L. infantum infection" (positive DNA sequencing for $L$. infantum following confirmatory qPCR and/or positive L. infantum ELISA), "Retroviral serology" (positive for FeLV and/or FIV serology) and "FVBP" [positive for at least one of the PCRs for B. henselae, Ehrlichia/ Anaplasma spp. and/or Hepatozoon spp., and/or $L$. infantum infection (i.e. positive DNA sequencing for $L$. infantum following confirmatory qPCR and/or positive L. infantum ELISA)].

The Kolmogorov-Smirnov test was used to assess for normality of distribution of the continuous variable age. Mann-Whitney U-tests were then used to evaluate for differences between non-normally distributed variable of age across infectious agent group(s). Initial analyses using Chi-square test was performed to evaluate any associations between the 19 categorical variables across individual infectious agent group(s). Multivariable logistic regression was used to test for possible risk factors associated with infection. Independent variables that yielded $P$-values of $<0.2$ in a univariable analysis were then tested in a multivariable logistic regression analysis. Backward selection was used primarily, and once a final model was constructed all the previously excluded variables were then individually retested and, if then significant, were included within the final model. Within the final multivariable models a $P$-value $\leq 0.05$ was considered statistically significant for inclusion, and the $P$-values with odds ratio (OR) and 95\% confidence interval $(\mathrm{CI})$ are reported.

\section{Results}

Of the 176 DNA samples analysed, two were excluded due to failure of one or more of the internal amplification control qPCRs, hence 174 samples were used in the study and subsequent statistical analyses. The age of these 174 cats ranged from 0.4 to 22.0 years (median 5.6 years, interquartile range 8 years) and only $15(8.6 \%)$ were pedigree including six Ragdolls, six Persians, two Siamese and one Russian Blue. Tables 2 and 3 show descriptive statistics as well as data on the prevalence of infectious agents among the population studied.

Specificity testing for the novel PCR assay for Hepatozoon spp. against B. canis, Babesia rossi, E. canis, A. phagocytophilum, L. infantum, B. clarridgeiae, Mhf, CMhm, CMt, $M$. haemocanis, "Ca. M. haematoparvum", N. caninum and T. gondii DNA found no evidence of cross-reactivity. 
Table 2 Comparison of prevalence of infectious agents detected by PCR in cats from Cyprus per categorical variable

\begin{tabular}{|c|c|c|c|c|c|c|c|c|}
\hline \multirow[t]{2}{*}{ Variable/category } & \multirow{2}{*}{$\begin{array}{l}\text { No. of } \\
\text { cats (\%) }\end{array}$} & \multicolumn{7}{|c|}{ No. of PCR positive cats (\%) } \\
\hline & & $\overline{M h f}$ & CMhm & CMt & Any hp & Hepatozoon spp. & B. henselae & L. infantum \\
\hline Gender & 174 & & & & & & & \\
\hline Male & $96(55.2)$ & $7(7.3)$ & $21(21.9)$ & $6(6.3)$ & $25(26.0)$ & $34(35.4)$ & $10(10.4)$ & $2(2.1)$ \\
\hline Female & $78(44.8)$ & $6(7.7)$ & $15(19.2)$ & $6(7.7)$ & $21(26.9)$ & $32(41.0)$ & $9(11.5)$ & $2(2.6)$ \\
\hline Breed & 174 & & & & & & & \\
\hline Non-Pedigree & $159(91.4)$ & $13(8.2)$ & $35(22.0)$ & $12(7.6)$ & $45(28.3)$ & $65(40.9)$ & $19(12.0)$ & $4(3.8)$ \\
\hline Pedigree & $15(8.6)$ & $0(0)$ & $1(6.7)$ & $0(0)$ & $1(6.7)$ & $1(6.7)$ & $0(0)$ & $0(0)$ \\
\hline Housing & 174 & & & & & & & \\
\hline Access to outdoors & $134(77.0)$ & $13(9.7)$ & $35(26.1)$ & $10(7.5)$ & $44(32.8)$ & $55(41.1)$ & $17(12.7)$ & $4(3.0)$ \\
\hline Indoors only & $40(23.0)$ & $0(0)$ & $1(2.5)$ & $2(5.0)$ & $2(5.0)$ & $11(27.5)$ & $2(5.0)$ & $0(0)$ \\
\hline Lifestyle & 174 & & & & & & & \\
\hline Shelter-feral & $36(20.7)$ & $5(13.9)$ & $24(66.6)$ & $6(16.7)$ & $14(38.9)$ & $20(55.6)$ & $6(16.7)$ & $1(2.8)$ \\
\hline Owned & $138(79.3)$ & $8(5.8)$ & $12(8.7)$ & $6(4.3)$ & $32(23.2)$ & $46(33.3)$ & $13(9.4)$ & $3(2.2)$ \\
\hline District & 174 & & & & & & & \\
\hline Paphos & 59 (33.9) & $4(6.8)$ & $14(23.7)$ & $4(6.8)$ & $16(27.1)$ & $23(39.0)$ & $10(17.0)$ & $4(6.8)$ \\
\hline Nicosia & $51(29.4)$ & $3(5.9)$ & $7(13.7)$ & $2(3.9)$ & $10(19.6)$ & $21(41.2)$ & $4(7.8)$ & $0(0)$ \\
\hline Larnaca & $28(16.1)$ & $2(7.1)$ & $5(17.9)$ & $1(3.6)$ & $6(21.4)$ & $8(28.6)$ & $2(7.1)$ & $0(0)$ \\
\hline Limassol & $22(12.6)$ & $2(9.1)$ & $8(36.4)$ & $3(13.6)$ & $9(40.9)$ & $7(31.8)$ & $3(13.6)$ & $0(0)$ \\
\hline Famagousta & $7(4.0)$ & $0(0)$ & $0(0)$ & $0(0)$ & $0(0)$ & $4(57.1)$ & $0(0)$ & $0(0)$ \\
\hline Kyrenia & $7(4.0)$ & $2(28.6)$ & $2(28.6)$ & $2(28.6)$ & $5(71.4)$ & $3(42.9)$ & $0(0)$ & $0(0)$ \\
\hline Habitat & 174 & & & & & & & \\
\hline Rural & $65(37.4)$ & $7(10.8)$ & $17(26.2)$ & $6(9.2)$ & $21(32.3)$ & $33(50.8)$ & $8(12.3)$ & $2(3.1)$ \\
\hline Urban & $109(62.6)$ & $6(5.5)$ & $19(17.4)$ & $6(5.5)$ & $25(22.9)$ & $33(30.3)$ & $11(10.1)$ & $2(1.8)$ \\
\hline Travel history & 174 & & & & & & & \\
\hline Never travelled abroad & $159(91.4)$ & $13(8.2)$ & $32(20.1)$ & $11(6.9)$ & $42(26.4)$ & $65(40.9)$ & $17(10.7)$ & $4(2.5)$ \\
\hline Travelled abroad & $15(8.6)$ & $0(0)$ & $4(26.7)$ & $1(6.7)$ & $4(26.7)$ & $1(6.7)$ & $2(13.3)$ & $0(0)$ \\
\hline Health status & 174 & & & & & & & \\
\hline Non-healthy & $131(75.3)$ & $12(9.2)$ & $33(25.2)$ & $9(6.9)$ & $41(31.3)$ & $58(44.3)$ & $14(10.7)$ & $4(3.1)$ \\
\hline Healthy & $43(24.7)$ & $1(2.3)$ & $3(6.9)$ & $3(7.0)$ & $5(11.6)$ & $8(18.6)$ & $5(11.6)$ & $0(0)$ \\
\hline Vaccination status & 165 & & & & & & & \\
\hline Never vaccinated & $47(28.5)$ & $8(17.0)$ & $9(19.2)$ & $7(14.9)$ & $14(29.8)$ & $25(53.2)$ & $4(8.5)$ & $1(2.1)$ \\
\hline Vaccinated & $118(71.5)$ & $5(4.2)$ & $23(19.5)$ & $5(4.2)$ & $28(23.7)$ & $36(30.5)$ & $15(12.7)$ & $3(2.5)$ \\
\hline Ectoparasitic prevention status & 165 & & & & & & & \\
\hline Never used & $62(37.6)$ & $8(12.9)$ & $15(24.2)$ & $7(11.3)$ & $21(33.9)$ & $31(50.0)$ & $9(14.5)$ & $2(3.2)$ \\
\hline Used & $103(62.4)$ & $5(4.9)$ & $17(16.5)$ & $5(4.9)$ & $21(20.4)$ & $30(29.1)$ & $10(9.7)$ & $2(1.9)$ \\
\hline Anaemia & 132 & & & & & & & \\
\hline Anaemic & $29(22.0)$ & $3(10.4)$ & $9(31.0)$ & $3(10.3)$ & $9(31.0)$ & $13(44.8)$ & $3(10.4)$ & 1 (3.5) \\
\hline Non-anaemic & $103(78.0)$ & $6(5.8)$ & $18(17.5)$ & $5(4.9)$ & $23(22.3)$ & $33(32.0)$ & $16(15.5)$ & $3(2.9)$ \\
\hline FeLV & 164 & & & & & & & \\
\hline Positive & $10(6.1)$ & $1(10.0)$ & $3(30.0)$ & $2(20.0)$ & $3(30.0)$ & $5(50.0)$ & $0(0)$ & $1(10.0)$ \\
\hline Negative & $154(93.9)$ & $10(6.5)$ & $30(19.5)$ & $9(5.8)$ & $39(25.3)$ & $59(38.3)$ & $18(11.7)$ & $3(2.0)$ \\
\hline FIV & 164 & & & & & & & \\
\hline Positive & 31 (18.9) & $4(12.9)$ & $17(54.8)$ & $7(22.6)$ & 19 (61.3) & $17(54.8)$ & $5(16.1)$ & $1(3.2)$ \\
\hline Negative & $133(81.1)$ & $7(5.3)$ & $16(12.0)$ & $4(3.0)$ & $23(17.3)$ & $47(35.3)$ & $13(9.8)$ & $3(2.3)$ \\
\hline Total & 174 & $13(7.5)$ & $36(20.7)$ & $12(6.9)$ & $46(26.4)$ & 66 (37.9) & $19(10.9)$ & $4(2.3)$ \\
\hline
\end{tabular}

Abbreviations: Mhf Mycoplasma haemofelis, CMhm "Candidatus Mycoplasma haemominutum", CMt "Candidatus Mycoplasma turicensis", Any hp positivity in at least one of the following haemoplasma PCR; Mhf, CMhm and CMt, B. henselae Bartonella henselae, L. infantum Leishmania infantum confirmed by DNA sequencing following confirmatory quantitative PCR, FeLV feline leukaemia virus, FIV feline immunodeficiency virus Note: Only one cat was positive for Ehrlichia/Anaplasma spp. PCR and information regarding this case is reported in the results section of the main text 
Table 3 Comparison of prevalence of infectious agents in cats detected by serology from Cyprus per categorical variable

\begin{tabular}{|c|c|c|c|c|c|}
\hline \multirow[t]{2}{*}{ Variable/category } & \multirow{2}{*}{$\begin{array}{l}\text { No. of } \\
\text { cats (\%) }\end{array}$} & \multicolumn{2}{|c|}{ No. of serology positive cats (\%) } & \multirow{2}{*}{$\begin{array}{l}\text { No. of } \\
\text { cats (\%) }\end{array}$} & \multirow{2}{*}{$\begin{array}{l}\text { No. of serology } \\
\text { positive cats for } \\
\text { L. infantum (\%) }\end{array}$} \\
\hline & & FeLV & FIV & & \\
\hline Gender & 164 & & & 160 & \\
\hline Male & $88(53.7)$ & $7(8.0)$ & $18(20.5)$ & $86(53.8)$ & $3(3.5)$ \\
\hline Female & $76(46.3)$ & $3(4.0)$ & $13(17.1)$ & $74(46.2)$ & $4(5.4)$ \\
\hline Breed & 164 & & & 160 & \\
\hline Non-Pedigree & $149(90.9)$ & $10(6.7)$ & $31(20.8)$ & $147(91.9)$ & $7(4.8)$ \\
\hline Pedigree & $15(9.2)$ & $0(0)$ & $0(0)$ & $13(8.1)$ & $0(0)$ \\
\hline Housing & 164 & & & 160 & \\
\hline Access to outdoors & $125(76.2)$ & $5(4.0)$ & $29(23.2)$ & $124(77.5)$ & $7(5.7)$ \\
\hline Indoors only & $39(23.8)$ & $5(12.8)$ & $2(5.1)$ & $36(22.5)$ & $0(0)$ \\
\hline Lifestyle & 164 & & & 160 & \\
\hline Shelter-feral & $33(20.1)$ & $1(3.0)$ & $14(42.4)$ & $33(20.6)$ & $3(9.1)$ \\
\hline Owned & $131(79.9)$ & $9(6.9)$ & $17(13.0)$ & $127(79.4)$ & $4(3.2)$ \\
\hline District & 164 & & & 160 & \\
\hline Paphos & $57(34.8)$ & $1(1.8)$ & $13(22.8)$ & $56(35.0)$ & $1(1.8)$ \\
\hline Nicosia & $48(29.3)$ & $1(2.1)$ & $8(16.7)$ & $44(27.5)$ & $3(6.8)$ \\
\hline Larnaca & $25(15.2)$ & $3(12.0)$ & $3(12.0)$ & $26(16.3)$ & $0(0)$ \\
\hline Limassol & $21(12.8)$ & $2(9.5)$ & $5(23.8)$ & $21(13.1)$ & $3(14.3)$ \\
\hline Famagousta & $7(4.3)$ & $1(14.3)$ & $0(0)$ & $7(4.4)$ & $0(0)$ \\
\hline Kyrenia & $6(3.7)$ & $2(33.3)$ & $2(33.3)$ & $6(3.7)$ & $0(0)$ \\
\hline Habitat & 164 & & & 160 & \\
\hline Rural & $60(36.6)$ & $3(5.0)$ & $13(21.7)$ & $62(38.8)$ & $3(4.8)$ \\
\hline Urban & $104(63.4)$ & $7(6.7)$ & $18(17.3)$ & $98(61.2)$ & $4(4.1)$ \\
\hline Travel history & 164 & & & 160 & \\
\hline Never travelled abroad & $149(90.9)$ & $10(6.7)$ & $27(18.1)$ & 145 (90.6) & $7(4.8)$ \\
\hline Travelled abroad & $15(9.2)$ & $0(0)$ & $4(26.7)$ & $15(9.4)$ & $0(0)$ \\
\hline Health status & 164 & & & 160 & \\
\hline Non-healthy & $123(75.0)$ & $10(8.1)$ & $29(23.6)$ & $117(73.1)$ & $6(5.1)$ \\
\hline Healthy & $41(25.0)$ & $0(0)$ & $2(4.9)$ & $43(26.9)$ & $1(2.3)$ \\
\hline Vaccination status & 156 & & & 151 & \\
\hline Never vaccinated & 43 (27.6) & $4(9.3)$ & $8(18.6)$ & $43(28.5)$ & $4(9.3)$ \\
\hline Vaccinated & $113(72.4)$ & $6(5.3)$ & $20(17.7)$ & $108(71.5)$ & $2(1.9)$ \\
\hline Ectoparasitic prevention status & 156 & & & 151 & \\
\hline Never used & $57(36.5)$ & $2(3.5)$ & $15(26.3)$ & $58(38.4)$ & $4(6.9)$ \\
\hline Used & $99(63.5)$ & $8(8.1)$ & $13(13.1)$ & $93(61.6)$ & $2(2.2)$ \\
\hline Anaemia & 128 & & & 120 & \\
\hline Anaemic & $28(21.9)$ & $4(14.3)$ & $10(35.7)$ & $28(23.3)$ & $2(7.1)$ \\
\hline Non-anaemic & $100(78.1)$ & $3(3.0)$ & $15(15.0)$ & $92(76.7)$ & $1(1.1)$ \\
\hline Total & 164 & $10(6.1)$ & $31(18.9)$ & 160 & $7(4.4)$ \\
\hline
\end{tabular}

Abbreviations: FeLV feline leukaemia virus, FIV feline immunodeficiency virus

Analytical sensitivity of the assay was assessed as follows. An amplicon from a known $H$. canis positive sample was quantified using a Qubit $^{\mathrm{Tm}}$ fluorometer (Invitrogen ${ }^{\mathrm{Tm}}$ ) and gave $13.2 \mathrm{ng} / \mu \mathrm{l}$. A 10 -fold serial dilution was made from $10^{-8}$ to $10^{-12}$, and each dilution was amplified in triplicate using the same conditions as described in the methods. Diluting the amplicon to $10^{-10}$ gave a 3 out of 3 success rate for detection and $10^{-11}$ a 2 out 
of 3 success rate; none of the triplicates at the $10^{-12}$ dilution gave a positive result. Using the amplicon length of $504 \mathrm{bp}$ and concentration of $13.2 \mathrm{ng} / \mu \mathrm{l}$, the theoretical limit of detection was calculated as being between 1.2 and 12 copies per PCR. Sequencing of the amplicons derived using the $H$. canis and $H$. felis known positive control DNA samples were found to match the expected $H$. canis or $H$. felis sequences.

Ninety-six (55.2\%) of the 174 cats were PCR-positive for at least one infectious agent, $79(45.4 \%)$ were positive to at least one FVBP while 17 (9.8\%) were positive for two FVBP (Table 4). Forty-six cats $(26.4 \%)$ were positive for haemoplasmas, including 13 (7.5\%) for Mhf, 36 (20.7\%) for CMhm and 12 (6.9\%) for CMt (Table 2). Sixty-six cats (37.9\%) were positive for Hepatozoon spp., while nineteen $(10.9 \%)$ were positive for B. henselae. One cat $(0.6 \%)$ was PCR positive for Ehrlichia/Anaplasma spp. This was a 19-year-old, neutered female, domestic shorthair cat from the Paphos area (rural) that was presented for monitoring of chronic kidney disease. The cat had lived in Greece for 12 years, was fully vaccinated, with access to the outdoors and was treated with a preventative ectoparasiticide. No abnormalities or $A$. platys morulae were found on haematological analysis and blood smear examination, and the cat was PCR positive only for Hepatozoon spp. and negative for the other infectious agents screened for in the study. Using the Leishmania spp. confirmatory qPCR assay, DNA was detected in 4 (2.3\%) of the 174 cats and L. infantum serology was positive in 7 of the 160 cats tested (4.4\%). Only one cat was positive by both Leishmania spp. confirmatory qPCR assay and serology, and additionally had cutaneous lesions caused by Leishmania infection

Table 4 Prevalence of single infections and co-infections with feline vector-borne pathogens including Bartonella henselae, Ehrlichia/Anaplasma spp. and Hepatozoon spp. determined by PCR, as well as Leishmania infantum infection, among 174 cats from Cyprus

\begin{tabular}{llr}
\hline Infectious agent(s) & \multicolumn{2}{c}{ Positive cats } \\
\cline { 2 - 3 } & No. & $\%$ \\
\hline Single infections & 62 & 35.7 \\
B. henselae & 11 & 6.3 \\
Hepatozoon spp. & 49 & 28.2 \\
L. infantum infection ${ }^{\text {a }}$ & 2 & 1.2 \\
Co-infections $_{\text {Ehrlichia/Anaplasma spp. and Hepatozoon spp. }}$ & 17 & 9.8 \\
B. henselae and Hepatozoon spp. & 1 & 0.6 \\
L. infantum infection $^{\text {a }}$ positive and Hepatozoon spp. & 8 & 4.6 \\
Total & 8 & 4.6 \\
\hline
\end{tabular}

${ }^{a}$ Positive $L$. infantum infection status defined as cats that had positive DNA sequencing for $L$. infantum following confirmatory qPCR and/or positive $L$. infantum ELISA reported by the veterinarian. Of the 164 cats that underwent retroviral serology, 10 (6.1\%) were FeLV, and 31 (18.9\%) were FIV, positive (Table 3).

Out of the 66 samples that were positive for Hepatozoon spp., 14 amplicons (accession numbers KY215805 to KY215818) were sequenced and yielded $96-100 \%$ similarity to an existing partial $18 \mathrm{~S}$ rRNA gene for $H$. felis (KC138534) over $504 \mathrm{bp}$. The cat that was positive on the generic Ehrlichia/Anaplasma spp. PCR yielded an amplicon (KY212527) that had $99 \%$ similarity to a partial 16S rRNA gene sequence of $A$. platys (KY114935) over $225 \mathrm{bp}$. The four amplicons of the positive confirmatory Leishmania spp. qPCR (Additional file 1) had 93-98\% similarity to kinetoplast DNA from an existing GenBank sequence for L. infantum (Z35292) over $122 \mathrm{bp}$.

Univariable analysis showed that many variables had a trend toward significance $(P<0.2)$ for association with the presence of individual, or groups of infectious agent(s) (Table 5, Table 6, Additional file 2: Table S1, Additional file 3: Table S2), and these were entered into the multivariable logistic regression analysis, together with variables having significant associations $(P \leq 0.05)$.

Thirteen sets of multivariable logistic regression, one for each infectious agent or group of infectious agents, were constructed using the independent variables that showed at least a trend towards significance $(P<0.2)$ in the univariable analysis. Eight multivariable models yielded significant associations $(P \leq 0.05)$ (Table 7$)$. No multivariable models yielded significant associations for Mhf, B. henselae, L. infantum PCR, L. infantum serology or FeLV.

\section{Discussion}

This is the first large-scale study to provide an overview of infectious agents in cats from Cyprus. Feline haemoplasmas, B. henselae, Hepatozoon spp. (including $H$. felis), L. infantum and A. platys were detected by PCR (with or without sequencing), while serology revealed infections with FeLV, FIV and L. infantum in the feline population of this island. Additionally, significant associations were identified between infectious agents and independent, risk factor variables using multivariable logistic regression, providing a better understanding of the epidemiology and possible risk factors for these infectious agents.

Over the last few decades, feline hepatozoonosis has been increasingly reported worldwide with prevalences being frequently low, but ranging up to $36 \%$ depending on geographical location and lifestyle of cats $[11,13,15,27-30]$. The exact vectors and routes of transmission of feline hepatozoonoses are not known [27], but vectorial transmission likely plays a key role as for other species of Hepatozoon 


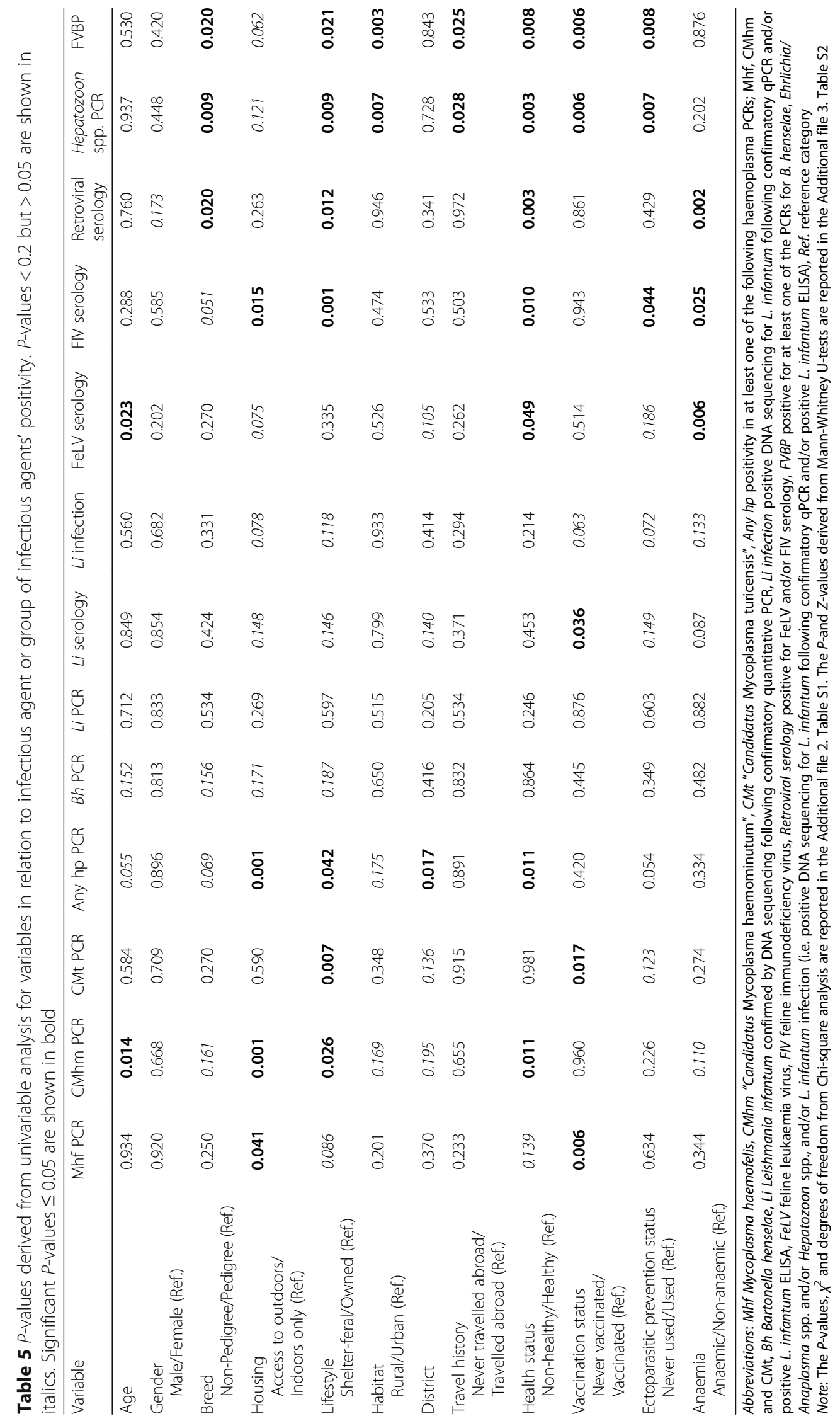




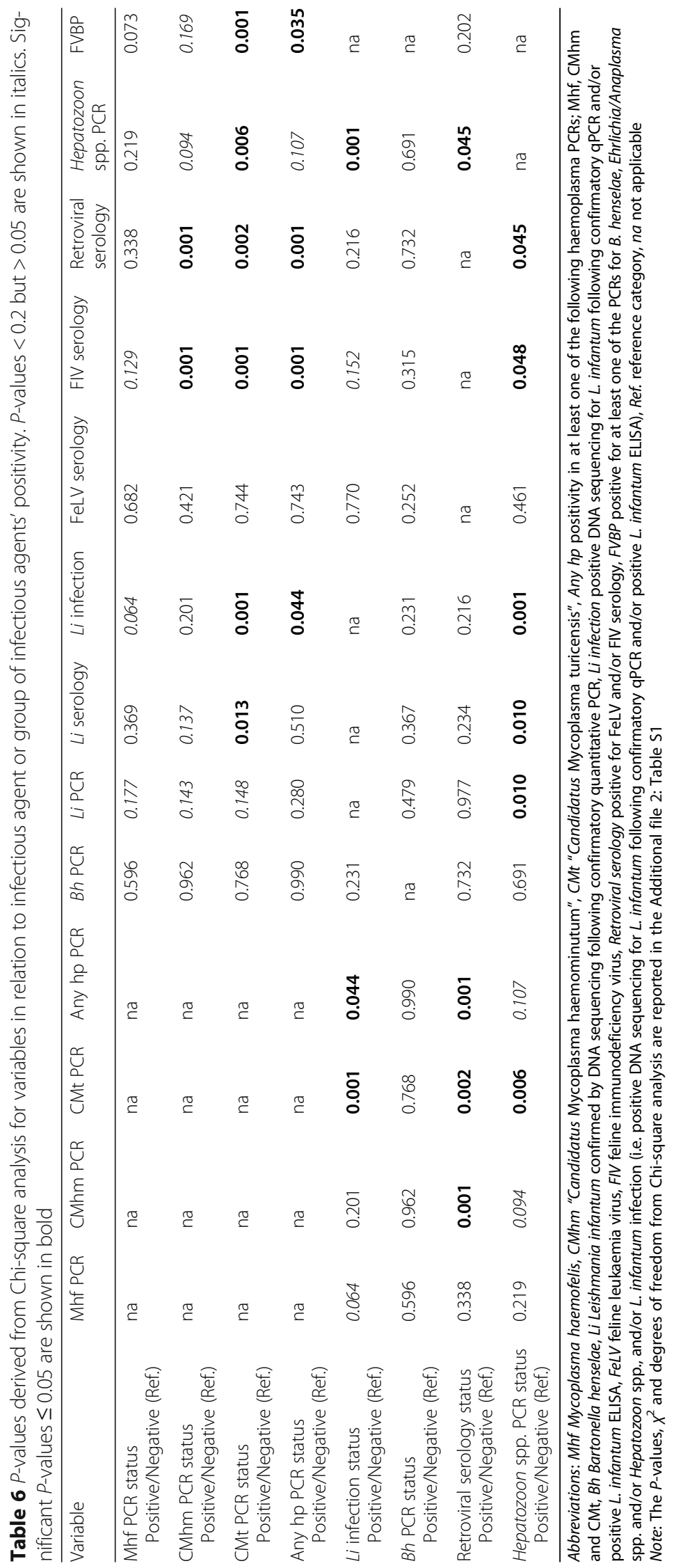


Table 7 Variables for the positivity of infectious agents or groups of infectious agents in cats in Cyprus: multivariable logistic regression models

\begin{tabular}{|c|c|c|}
\hline & Odds ratio $(95 \% \mathrm{Cl})$ & $P$-value \\
\hline \multicolumn{3}{|l|}{ 1. CMhm PCR positive } \\
\hline \multicolumn{3}{|c|}{ Retroviral serology status } \\
\hline Positive & $5.8(2.4-14.0)$ & 0.001 \\
\hline Negative & Ref. & \\
\hline Age & $1.1(1.1-1.2)$ & 0.017 \\
\hline \multicolumn{3}{|l|}{ Lifestyle } \\
\hline Shelter-feral & $2.8(1.1-7.4)$ & 0.043 \\
\hline Owned & Ref. & \\
\hline \multicolumn{3}{|l|}{ 2. CMt PCR positive } \\
\hline \multicolumn{3}{|c|}{ L. infantum infection status } \\
\hline Positive & $7.3(1.4-37.5)$ & 0.018 \\
\hline Negative & Ref. & \\
\hline \multicolumn{3}{|c|}{ Retroviral serology status } \\
\hline Positive & $5.0(1.3-219.7)$ & 0.021 \\
\hline Negative & Ref. & \\
\hline \multicolumn{3}{|c|}{ 3. Any haemoplasma PCR positive } \\
\hline \multicolumn{3}{|c|}{ Retroviral serology status } \\
\hline Positive & $4.6(2.1-10.4)$ & 0.001 \\
\hline Negative & Ref. & \\
\hline \multicolumn{3}{|l|}{ Housing } \\
\hline Access to outdoors & $8.7(1.9-39.1)$ & 0.005 \\
\hline Indoors only & Ref. & \\
\hline \multicolumn{3}{|c|}{ 4. L. infantum infection positive } \\
\hline \multicolumn{3}{|c|}{ Hepatozoon spp. PCR status } \\
\hline Positive & $13.5(1.6-111.1)$ & 0.016 \\
\hline Negative & Ref. & \\
\hline \multicolumn{3}{|l|}{ CMt PCR status } \\
\hline Positive & $5.6(1.1-29.1)$ & 0.041 \\
\hline Negative & Ref. & \\
\hline \multicolumn{3}{|l|}{ 5. FIV serology positive } \\
\hline \multicolumn{3}{|c|}{ Any haemoplasma PCR status } \\
\hline Positive & $6.6(2.7-15.9)$ & 0.001 \\
\hline Negative & Ref. & \\
\hline \multicolumn{3}{|l|}{ Lifestyle } \\
\hline Shelter-feral & $4.0(1.6-10.2)$ & 0.004 \\
\hline Owned & Ref. & \\
\hline
\end{tabular}

Table 7 Variables for the positivity of infectious agents or groups of infectious agents in cats in Cyprus: multivariable logistic regression models (Continued)

\begin{tabular}{|c|c|c|}
\hline \multicolumn{3}{|l|}{ 6. Retroviral serology positive } \\
\hline \multicolumn{3}{|c|}{ Any haemoplasma PCR status } \\
\hline Positive & $5.3(2.1-13.4)$ & 0.001 \\
\hline Negative & Ref. & \\
\hline \multicolumn{3}{|l|}{ Anaemia } \\
\hline Anaemic & $3.6(1.4-9.5)$ & 0.008 \\
\hline Non-anaemic & Ref. & \\
\hline \multicolumn{3}{|c|}{ 7. Hepatozoon spp. PCR positive } \\
\hline \multicolumn{3}{|l|}{ Health status } \\
\hline Non-healthy & $3.2(1.3-7.8)$ & 0.010 \\
\hline Healthy & Ref. & \\
\hline \multicolumn{3}{|l|}{ L. infantum infection status } \\
\hline Positive & $12.0(1.4-106.0)$ & 0.025 \\
\hline Negative & Ref. & \\
\hline \multicolumn{3}{|l|}{ Vaccination status } \\
\hline Never vaccinated & $2.2(1.1-4.7)$ & 0.048 \\
\hline Vaccinated & Ref. & \\
\hline \multicolumn{3}{|l|}{ 8. FVBP positive } \\
\hline \multicolumn{3}{|l|}{ Habitat status } \\
\hline Rural & $2.6(1.3-5.2)$ & 0.006 \\
\hline Urban & Ref. & \\
\hline \multicolumn{3}{|l|}{ CMt PCR status } \\
\hline Positive & $22.5(2.3-221.2)$ & 0.008 \\
\hline Negative & Ref. & \\
\hline \multicolumn{3}{|l|}{ Health status } \\
\hline Non-healthy & $2.4(1.1-5.4)$ & 0.042 \\
\hline Healthy & Ref. & \\
\hline \multicolumn{3}{|l|}{ Travel history } \\
\hline Never travelled abroad & $4.3(1.1-18.0)$ & 0.045 \\
\hline Travelled abroad & Ref. & \\
\hline
\end{tabular}

Abbreviations: $\mathrm{Cl}$ confidence interval, Ref. reference category, CMhm "Candidatus Mycoplasma haemominutum", CMt "Candidatus Mycoplasma turicensis", L. infantum infection positive DNA sequencing for Leishmania infantum following confirmatory $\mathrm{qPCR}$ and/or positive L. infantum ELISA, Any haemoplasma positivity in at least one of the following haemoplasma PCRs; Mhf, CMhm and CMt, FIV feline immunodeficiency virus, Retroviral serology positive for FeLV and/or FIV serology, FVBP positive for at least one of the PCRs for B. henselae, Ehrlichia/Anaplasma spp. and/or Hepatozoon spp., and/or L. infantum infection (i.e. positive DNA sequencing for $L$. infantum following confirmatory $q P C R$ and/ or positive L. infantum ELISA)

in different vertebrate species such as dogs [31]. The results of the present study demonstrate the utility of the novel Hepatozoon spp. PCR assay for the detection of $H$. canis and $H$. felis and the absence of cross-reaction with a range of other pathogens. In this study, we found a prevalence of $37.9 \%$ for 
Hepatozoon spp. infection in cats, with an even higher prevalence of $55.5 \%$ in shelter-feral cats. Amplicon sequencing revealed the presence of $H$. felis only, but we cannot rule out the possibility of some cats being infected with $H$. canis since not all positive PCR products were sequenced due to financial constraints, and $H$. canis has been previously reported to infect cats [27] and has been described in Cyprus [17]. Univariable statistical analysis revealed ten variables associated with Hepatozoon spp. infection from which three (non-healthy, L. infantum infection positive status and never vaccinated) remained statistically significant in the multivariable logistic regression model. To our knowledge, this is the first time that associations have been found using multivariable logistic regression for feline hepatozoonosis. The association $(\mathrm{OR}=3.2,95 \% \mathrm{CI}: 1.3-7.8$, $P=0.010$ ) between Hepatozoon spp. infection and health status, with non-healthy cats being three times more likely to be Hepatozoon spp. infected compared to healthy cats, is interesting since feline hepatozoonosis has been described as being predominantly a sub-clinical infection [27]. This association does not necessarily mean that the cause of the cats' ill-health was hepatozoonosis, especially since the cats were often co-infected with other pathogens; therefore further studies are needed to identify the clinical implications of hepatozoonosis in cats. Cats with a positive L. infantum infection status were 12 times more likely to be infected with Hepatozoon spp. (OR $=12.0$, 95\% CI: 1.4-106.0, $P=0.025)$ compared to cats with $L$. infantum infection negative status. This co-infection is commonly reported in dogs with $H$. canis [32], and it is the first time that such association has been reported in cats. Co-infection with these two protozoans might lead to higher level of circulating parasites due to impaired response of the host immune system [33]. The reason for the significant association between Hepatozoon spp. infection and negative vaccination status is unknown, but could be due to an association with an overall lack of preventative health care.

Similar to dogs, L. infantum infection in cats is most likely transmitted by phlebotomine sand flies and is currently an emerging zoonotic infectious disease [34]. The current study's findings of a L. infantum PCR-based prevalence of $2.3 \%$ (confirmed by DNA sequencing following confirmatory quantitative PCR), L. infantum seroprevalence of $4.4 \%$ and a combined infection (i.e. positive DNA sequencing for L. infantum following confirmatory $\mathrm{qPCR}$ and/or positive $L$. infantum ELISA) prevalence of $5.8 \%$, are similar to those reported in other Mediterranean countries [15, 26, 35, 36], although lower than the $14.9 \%$ seroprevalence in dogs from Cyprus [6]. Only one sick cat, which had cutaneous lesions caused by Leishmania infection, was positive by both serology and PCR with confirmed $L$. infantum on sequencing. Sequencing showed L. infantum in another three cats, and this agreed with a previous study in Cyprus on dogs, where also only $L$. infantum was found [6]. The variables of male gender, adult age, rural habitat [37], outdoor lifestyle [34] and retroviral positivity [26], which are all previously reported risk factors for leishmaniosis in cats, were not found to be significant in this study. However, significant associations between $L$. infantum infection status and infection with Hepatozoon spp. $(\mathrm{OR}=13.5$, 95\% CI: $1.6-111.1, P=0.016)$ and CMt (OR $=5.6,95 \%$ CI: $1.1-29.1, P=0.041$ ) were found by multivariable logistic regression. Possible causes of these associations may reflect pathogen-facilitation or phenotypic traits (e.g. aggressiveness) that were not recorded during the study [38].

The prevalence of haemoplasma infection in cats in this study was similar to those reported in other European countries [10, 39-45], with CMhm infection being most common, followed by Mhf and CMt. Multivariable logistic regression analyses (Table 7) showed significant associations between positive retroviral status and each of CMhm (OR = 5.8, 95\% CI: 2.4-14.0, $P=0.001$ ), CMt $(\mathrm{OR}=5.0,95 \%$ CI: $1.3-219.7, P=0.021)$ and overall haemoplasma infection $(\mathrm{OR}=4.6,95 \% \mathrm{CI}: 2.1-10.4$, $P=0.001$ ). This supports the previous reports that retroviral infections, especially FIV, are risk factors for haemoplasma infection [43, 46]. Consistent with previous studies [40, 45-47], our study also identified additional risk factors including age $(O R=1.1$, 95\% CI: $1.1-1.2, P=0.017)$ and being a shelter-feral cat $(\mathrm{OR}=2.8,95 \% \mathrm{CI}: 1.1-7.4, P=0.043)$ for $\mathrm{CMhm}$ infection, and access to outdoors $(\mathrm{OR}=8.7,95 \% \mathrm{CI}$ : 1.9-39.1, $P=0.005)$ for infection with any haemoplasma species. Interestingly, this is the first time $L$. infantum infection in cats $(\mathrm{OR}=7.3,95 \% \mathrm{CI}$ : $1.4-$ $37.5, P=0.018$ ) has been associated with CMt infection, with Leishmania infected cats being seven times more likely to be CMt-positive.

Molecular investigation detected B. henselae in 10.9\% of the cats in this study, which is amongst the highest prevalence of infection reported in Europe $[9-11,15,16]$. A recent study from southern Italy [9] reported a $21.4 \%$ PCR prevalence of $B$. henselae in outdoor cats that had at least one ectoparasite (tick or flea) present on examination. In the current study both indoor and outdoor cats were included, but ectoparasite presence was not assessed. Despite being a zoonotic infection, this is the first time that $B$. henselae has been detected in Cyprus, although $10.5 \%$ of rats in Cyprus have been shown to be seropositive for B. henselae [48]. Other Bartonella species could possibly exist in Cyprus, but were not investigated, thus further studies are needed. 
In our study, 18.9 and $6.1 \%$ of the cats were seropositive for FIV and FeLV, respectively, findings which are similar to those reported in previous studies [49-53]. Multivariable logistic regression revealed significant associations between FIV and haemoplasma infection $(\mathrm{OR}=6.6,95 \%$ CI: $2.7-15.9, P=0.001)$ and FIV infection and shelter-feral cats $(\mathrm{OR}=4.0,95 \% \mathrm{CI}: 1.6-10.2, P=0.004)$. In addition, overall retroviral infection was associated with haemoplasma infection $(\mathrm{OR}=5.3,95 \% \mathrm{CI}$ : $2.1-13.4, P=0.001)$ and anaemia $(\mathrm{OR}=3.6,95 \% \mathrm{CI}$ : $1.4-9.5, P=0.008)$. To our knowledge, this is the first time multivariable logistic regression has documented an association of seropositivity with shelter-feral cats, and retroviral seropositivity with anaemia.

Anaplasma platys is considered a VBP, that is widespread in dogs from the Mediterranean basin and has also been reported in dogs, sheep and goats from Cyprus [17, 54, 55]. There are sporadic reports of this canine pathogen in cats from North America and Brazil [7, 56, 57], and recently A. platys-like strains were identified in cats from Sardinia, Italy [58]. In this study, we report a case of presumptive $A$. platys infection in a cat from Cyprus based on partial sequencing of 16S rRNA gene. However, further investigation with additional phylogeny and amplification of multiple and longer genes are needed, in order to definitively prove the identity of this pathogen. In this case, as well as in the previous feline case reports $[56,57]$, the pathogenic role of $A$. platys in cats is not clear.

The overall prevalence of FVBP in this study is higher than those reported in studies performed in other southern European countries [9, 11, 13]. Logistic regression analyses showed significant associations between FVBP infection and rural habitat, as well as never having travelled abroad, indicating that such infections are largely driven by eco-environmental conditions favouring the infestation of arthropod vectors that transmit pathogens to cats. To date, no studies have investigated the presence of arthropod vectors in cats from Cyprus, however ectoparasites described in Cyprus include the ticks Rhipicephalus sanguineus, Rhipicephalus pusillus, Ixodes ventalloi [2], the cat flea Ctenocephalides felis [5] and phlebotomine sand flies such as Phlebotomus tobbi, Phlebotomus galilaeus, and Phlebotomus papatasi [6].

\section{Conclusions}

The results from this study demonstrate that FVBP, feline haemoplasmas and retroviral infections are present with considerable prevalence in the feline population of Cyprus. These findings should alert owners, the veterinary community and public health authorities to the possible risk of transmission of zoonotic FVBP including $B$. henselae and L. infantum. Priority should be given to establishing a surveillance system for arthropod vectors and FVBP in cats in order to monitor their distribution and prevent further spreading of these pathogens with regular effective prophylactic measures, such as the use of ectoparasite prevention in cats.

\section{Additional files}

Additional file 1: Sequences of the four amplicons from the positive confirmatory Leishmania spp. qPCR. (TXT 971 bytes)

Additional file 2: Table S1. $P$-values, $X^{2}$ and degrees of freedom derived from Chi-square analysis for variables in relation to infectious agent or group of infectious agents. (DOCX $35 \mathrm{~kb}$ )

Additional file 3: Table S2. $P$-and $Z$-values derived from Mann-Whitney $U$-tests for age in relation to infectious agent or group of infectious agents. (DOCX $16 \mathrm{~kb})$

\section{Abbreviations}

Cl: Confidence interval; CMhm: "Candidatus Mycoplasma haemominutum"; CMt: "Candidatus Mycoplasma turicensis"; Ct: Threshold cycle; FeLV: Feline leukaemia virus; FIV: Feline immunodeficiency virus; FVBP: Feline vector-borne pathogens; Mhf: Mycoplasma haemofelis; OR: Odds ratio; qPCR: Quantitative polymerase chain reaction; VBP: Vector-borne pathogens

\section{Acknowledgements}

The paper has been sponsored by Bayer Animal Health in the framework of the 12th CVBD World Forum Symposium. Authors would like also to thank all the veterinarians from Cyprus that helped in the collection of samples including Christos Yiapanis, Kyriaki Neofytou, Zacharias Evangelou, Nicoletta Kaparti, Stavroula Loukaidou, Pertev Karaligil, Nektaria loannou Arsenoglou, Panagiotis Kokkinos, Ionannis Karas, Maria Loizou, Tasos Kefalas, Nikolas Charalambous, Constantinos Constantinou, Christos Anthousis, Evis Andreou, Efstathia-Evangelia Georgiadi, Nicolas Monoyios, Michalis Louka, Paraskevi Pieri, Marianna Georgiou, George Vasiliou, Xenophon Diaouris, Thea Timotheou, Athinodoros Athinodorou and Christina Strati.

\section{Funding}

This clinical study has been sponsored by Bayer Animal Health in the framework of the $12^{\text {th }}$ CVBD World Forum Symposium, University of Bristol and a clinical research grant from Langford Vets, University of Bristol.

\section{Availability of data and materials}

The datasets supporting the conclusion of this article are included within the article and its additional files. Sequences were submitted to the GenBank database under accession numbers KY215805-KY215818 for $\mathrm{H}$. felis and KY212527 for A. platys.

\section{Authors' contributions}

$\mathrm{CA}, \mathrm{KP}, \mathrm{CH}$ and ST conceived the study and all participated in its design and coordinated the experiments. CA and SM designed and performed the collection of the samples. CA and DM extracted the DNA and performed PCR analysis. DM and $\mathrm{CH}$ designed and validated the novel Hepatozoon spp. assay. GB and YNB performed the Leishmania spp. sequencing and part of the Leishmania spp. PCR. CA and LSG performed the L. infantum ELISA. Statistical analysis was performed by CA, ES, TGK and ST. CA and ST wrote the manuscript with input from all the authors. All authors read and approved the final manuscript.

\section{Competing interests}

The authors declare that they have no competing interests.

Concent for publication

Not applicable. 


\section{Ethics approval}

This study was ethically approved by the University of Bristol's Animal Welfare and Ethical Review Board (Veterinary Investigation number: 14/037). All procedures were performed in accordance of the Cypriot legislation [The Dogs LAW, N. 184 (I)/2002] following diagnostic testing and with written owners' consent.

\section{Author details}

'Molecular Diagnostic Unit, Diagnostic Laboratories, Langford Vets and School of Veterinary Sciences, University of Bristol, Langford, UK. ${ }^{2}$ Cyvets Veterinary Center, Paphos, Cyprus. ${ }^{3}$ Departament de Medicina i Cirurgia Animals, Facultat de Veterinària, Universitat Autònoma de Barcelona, Barcelona, Spain. ${ }^{4}$ Koret School of Veterinary Medicine, Hebrew University, Rehovot, Israel. ${ }^{5}$ School of Veterinary Sciences, University of Bristol, Langford, UK. ${ }^{6}$ Petcare Veterinary Clinic, Nicosia, Cyprus.

\section{Received: 16 January 2017 Accepted: 24 February 2017}

\section{Published online: 13 March 2017}

\section{References}

1. Vigne J-D, Guilaine J, Debue K, Haye L, Gérard P. Early taming of the cat in Cyprus. Science. 2004;304:259

2. Chochlakis D, loannou I, Sandalakis V, Dimitriou T, Kassinis N, Papadopoulos B, et al. Spotted fever group Rickettsiae in ticks in Cyprus. Microb Ecol. 2012; 63:314-23.

3. Christou C, Psaroulaki A, Antoniou M, Toumazos P, loannou I, Mazeris A, et al. Rickettsia typhi and Rickettsia felis in Xenopsylla cheopis and Leptopsylla segnis parasitizing rats in Cyprus. Am J Trop Med Hyg. 2010;83:1301-4.

4. Violaris M, Vasquez MI, Samanidou A, Wirth MC, Hadjivassilis A. The mosquito fauna of the Republic of Cyprus: a revised list. J Am Mosq Control Assoc. 2009; 25:199-202.

5. Psaroulaki A, Antoniou M, Papaeustathiou A, Toumazos P, Loukaides F, Tselentis Y. Short report: first detection of Rickettsia felis in Ctenocephalides felis fleas parasitizing rats in Cyprus. Am J Trop Med Hyg. 2006;74:120-2.

6. Mazeris A, Soteriadou K, Dedet JP, Haralambous C, Tsatsaris A, Moschandreas J, et al. Leishmaniases and the Cyprus paradox. Am J Trop Med Hyg. 2010;82:441-8,

7. Hegarty BC, Qurollo BA, Thomas B, Park K, Chandrashekar R, Beall MJ, et al. Serological and molecular analysis of feline vector-borne anaplasmosis and ehrlichiosis using species-specific peptides and PCR. Parasit Vectors. 2015;8:320.

8. Otranto D, Dantas-Torres F. Canine and feline vector-borne diseases in Italy: current situation and perspectives. Parasit Vectors. 2010;3:2.

9. Persichetti M-F, Solano-Gallego L, Serrano L, Altet L, Reale S, Masucci M, et al. Detection of vector-borne pathogens in cats and their ectoparasites in southern Italy. Parasit Vectors. 2016;9:247.

10. Silaghi C, Knaus M, Rapti D, Kusi I, Shukullari E, Hamel D, et al. Survey of Toxoplasma gondii and Neospora caninum, haemotropic mycoplasmas and other arthropod-borne pathogens in cats from Albania. Parasit Vectors. 2014;7:62.

11. Maia C, Ramos C, Coimbra M, Bastos F, Martins A, Pinto P, et al. Bacterial and protozoal agents of feline vector-borne diseases in domestic and stray cats from southern Portugal. Parasit Vectors. 2014;7:115.

12. Aquino LC, Hicks CAE, Scalon MC, da Lima MG, dos Lemos MS, Paludo GR, et al. Prevalence and phylogenetic analysis of haemoplasmas from cats infected with multiple species. J Microbiol Methods. 2014;107:189-96.

13. Vilhena H, Martinez-Díaz VL, Cardoso L, Vieira L, Altet L, Francino O, et al. Feline vector-borne pathogens in the north and centre of Portugal. Parasit Vectors. 2013;6:99.

14. Lappin MR, Griffin B, Brunt J, Riley A, Burney D, Hawley J, et al. Prevalence of Bartonella species, haemoplasma species, Ehrlichia species, Anaplasma phagocytophilum, and Neorickettsia risticii DNA in the blood of cats and their fleas in the United States. J Feline Med Surg. 2006;8:85-90.

15. Tabar MD, Altet L, Francino O, Sánchez A, Ferrer L, Roura X. Vector-borne infections in cats: molecular study in Barcelona area (Spain). Vet Parasitol. 2008;151:332-6.

16. Solano-Gallego L, Hegarty B, Espada Y, Llull J, Breitschwerdt E. Serological and molecular evidence of exposure to arthropod-borne organisms in cats from northeastern Spain. Vet Microbiol. 2006:118:274-7.

17. Attipa C, Hicks CAE, Barker EN, Christodoulou V, Neofytou K, Mylonakis ME, et al. Canine tick-borne pathogens in Cyprus and a unique canine case of multiple co-infections. Ticks Tick Borne Dis. 2016;8:341-6.
18. Peters IR, Helps CR, Willi B, Hofmann-Lehmann R, Tasker S. The prevalence of three species of feline haemoplasmas in samples submitted to a diagnostics service as determined by three novel real-time duplex PCR assays. Vet Microbiol. 2008;126:142-50.

19. Shaw SE, Langton DA, Hillman TJ. Canine leishmaniosis in the united kingdom: a zoonotic disease waiting for a vector? Vet Parasitol. 2009:163:281-5.

20. Robinson MT, Morgan ER, Woods D, Shaw SE. Real-time and multiplex real-time polymerase chain reactions for the detection of Bartonella henselae within cat flea, Ctenocephalides felis, samples. Med Vet Entomol. 2010;24:449-55.

21. Parola P, Roux V, Camicas J-L, Baradji I, Brouqui Philippe RD. Detection of ehrlichiae in African ticks by polymerase chain reaction. Trans R Soc Trop Med Hyg. 2000;94:707-8.

22. Nicolas L, Milon G, Prina E. Rapid differentiation of Old World Leishmania species by LightCycler polymerase chain reaction and melting curve analysis. J Microbiol Methods. 2002;51:295-9.

23. Yasur-Landau D, Jaffe CL, David L, Baneth G. Allopurinol resistance in Leishmania infantum from dogs with disease relapse. PLoS Negl Trop Dis. 2016;10.

24. Inokuma H, Okuda M, Ohno K, Shimoda K, Onishi T. Analysis of the 185 rRNA gene sequence of a Hepatozoon detected in two Japanese dogs. Vet Parasitol. 2002;106:265-71.

25. Altschul SF, Gish W, Miller W, Myers EW, Lipman DJ. Basic local alignment search tool. J Mol Biol. 1990;215:403-10.

26. Sherry K, Miró G, Trotta M, Miranda C, Montoya A, Espinosa C, et al. A serological and molecular study of Leishmania infantum infection in cats from the Island of Ibiza (Spain). Vector Borne Zoonotic Dis. 2011;11:239-45.

27. Baneth G, Sheiner A, Eyal O, Hahn S, Beaufils J-P, Anug Y, et al. Redescription of Hepatozoon felis (Apicomplexa: Hepatozoidae) based on phylogenetic analysis, tissue and blood form morphology, and possible transplacental transmission. Parasit Vectors. 2013;6:102.

28. Lloret A, Addie DD, Boucraut-Baralon C, Egberink H, Frymus T, GruffyddJones $\mathrm{T}$, et al. Hepatozoonosis in cats ABCD guidelines on prevention and management. J Feline Med Surg. 2015;17:642-4.

29. Jittapalapong S, Rungphisutthipongse O, Maruyama S, Schaefer JJ, Stich RW. Detection of Hepatozoon canis in stray dogs and cats in Bangkok, Thailand. Ann NY Acad Sci. 2006.

30. Ortuño A, Castellà J, Criado-Fornelio A, Buling A, Barba-Carretero JC. Molecular detection of a Hepatozoon species in stray cats from a feline colony in Northeastern Spain. Vet J. 2008;177:134-5.

31. Baneth G, Samish M, Shkap V. Life cycle of Hepatozoon canis (Apicomplexa: Adeleorina: Hepatozoidae) in the tick Rhipicephalus sanguineus and domestic dog (Canis familiaris). J Parasitol. 2007;93:283-99.

32. Baneth G. Perspectives on canine and feline hepatozoonosis. Vet Parasitol. 2011;181:3-11.

33. Baneth G, Samish M, Alekseev E, Aroch I, Shkap V. Transmission of Hepatozoon canis to dogs by naturally-fed or percutaneously-injected Rhipicephalus sanguineus ticks. J Parasitol. 2001;87:606-11.

34. Pennisi M-G, Cardoso L, Baneth G, Bourdeau P, Koutinas A, Miró G, et al. Leishvet update and recommendations on feline leishmaniosis. Parasit Vectors. 2015;8:302.

35. Diakou A, Papadopoulos E, Lazarides K. Specific anti-Leishmania spp. antibodies in stray cats in Greece. J Feline Med Surg. 2009:11:728-30.

36. Nasereddin A, Salant H, Abdeen Z. Feline leishmaniasis in Jerusalem: serological investigation. Vet Parasitol. 2008:158:364-9.

37. Cardoso L, Lopes AP, Sherry K, Schallig H, Solano-Gallego L. Low seroprevalence of Leishmania infantum infection in cats from northern Portugal based on DAT and ELISA. Vet Parasitol. 2010;174:37-42.

38. Carver S, Beatty JA, Troyer RM, Harris RL, Stutzman-Rodriguez K, Barrs VR, et al. Closing the gap on causal processes of infection risk from cross-sectional data: structural equation models to understand infection and co-infection. Parasit Vectors. 2015;8:658

39. Martínez-Díaz VL, Silvestre-Ferreira AC, Vilhena H, Pastor J, Francino O, Altet L. Prevalence and co-infection of haemotropic mycoplasmas in Portuguese cats by real-time polymerase chain reaction. J Feline Med Surg. 2013

40. Maher IE, Tasker S, Polizopoulou Z, Dasopoulou A, Egan K, Helps CR, et al. Polymerase chain reaction survey of feline haemoplasma infections in Greece. J Feline Med Surg. 2010;12:601-5.

41. Willi B, Boretti FS, Baumgartner C, Tasker S, Wenger B, Cattori V, et al. Prevalence, risk factor analysis, and follow-up of infections caused by three feline hemoplasma species in cats in Switzerland. Am Soc Microbiol. 2006;44:961-9. 
42. Bennett AD, Gunn-Moore DA, Brewer M, Lappin MR. Prevalence of Bartonella species, haemoplasmas and Toxoplasma gondii in cats in Scotland. J Feline Med Surg. 2011;13:553-7.

43. Tasker S, Binns SH, Day MJ, Gruffydd-Jones TJ, Harbour DA, Helps CR, et al. Use of a PCR assay to assess the prevalence and risk factors for Mycoplasma haemofelis and "Candidatus Mycoplasma haemominutum" in cats in the United Kingdom. Vet Rec. 2003;152:193-8.

44. Roura X, Peters IR, Altet L, Tabar M-D, Barker EN, Planellas M, et al. Prevalence of hemotropic mycoplasmas in healthy and unhealthy cats and dogs in Spain. J Vet Diagn Invest. 2010;22:270-4.

45. Bauer N, Balzer HJ, Thüre S, Moritz A. Prevalence of feline haemotropic mycoplasmas in convenience samples of cats in Germany. J Feline Med Surg. 2008;10:252-8.

46. Jenkins KS, Dittmer KE, Marshall JC, Tasker S. Prevalence and risk factor analysis of feline haemoplasma infection in New Zealand domestic cats using a real-time PCR assay. J Feline Med Surg. 2013;15:1063-9.

47. Sykes JE, Drazenovich NL, Ball LM, Leutenegger CM. Use of conventional and real-time polymerase chain reaction to determine the epidemiology of hemoplasma infections in anemic and nonanemic cats. J Vet Intern Med. 2007;21:685-93.

48. Psaroulaki A, Antoniou M, Toumazos P, Mazeris A, loannou I, Chochlakis D, et al. Rats as indicators of the presence and dispersal of six zoonotic microbial agents in Cyprus, an island ecosystem: a seroepidemiological study. Trans R Soc Trop Med Hyg. 2010;104:733-9.

49. Bandecchi P, Matteucci D, Baldinotti F, Guidi G, Abramo F, Tozzini F, et al. Prevalence of feline immunodeficiency virus and other retroviral infections in sick cats in Italy. Vet Immunol Immunopathol. 1992;31:337-45.

50. Lee IT, Levy JK, Gorman SP, Crawford PC, Slater MR. Prevalence of feline leukemia virus infection and serum antibodies against feline immunodeficiency virus in unowned free-roaming cats. J Am Vet Med Assoc. 2002;220:620-2.

51. Westman ME, Paul A, Malik R, McDonagh P, Ward MP, Hall E, et al. Seroprevalence of feline immunodeficiency virus and feline leukaemia virus in Australia: risk factors for infection and geographical influences (2011-2013). J Feline Med Surg. Open Reports. 2016;2.

52. Gleich SE, Krieger S, Hartmann K. Prevalence of feline immunodeficiency virus and feline leukaemia virus among client-owned cats and risk factors for infection in Germany. J Feline Med Surg. 2009;11:985-92.

53. Hosie MJ, Robertson C, Jarrett O. Prevalence of feline leukaemia virus and antibodies to feline immunodeficiency virus in cats in the United Kingdom. Vet Rec. 1989;125:293-7.

54. Bouzouraa T, René-Martellet M, Chêne J, Attipa C, Lebert I, Chalvet-Monfray $\mathrm{K}$, et al. Clinical and laboratory features of canine Anaplasma platys infection in 32 naturally infected dogs in the Mediterranean basin. Ticks Tick Borne Dis. 2016:1256-64.

55. Chochlakis D, loannou I, Sharif L, Kokkini S, Hristophi N, Dimitriou T, et al. Prevalence of Anaplasma sp. in goats and sheep in Cyprus. Vector Borne Zoonotic Dis. 2009;9:457-63.

56. Qurollo BA, Balakrishnan N, Zegre CC, Maggi RG, Breitschwerdt EB. Co-infection with Anaplasma platys, Bartonella henselae, Bartonella koehlerae and "Candidatus Mycoplasma haemominutum" in a cat diagnosed with splenic plasmacytosis and multiple myeloma. J Feline Med Surg. 2014;16:713-20.

57. Lima MLF, Soares PT, Ramos CAN, Araújo FR, Ramos RAN, Souza IIF, et al. Molecular detection of Anaplasma platys in a naturally-infected cat in Brazil. Braz J Microbiol. 2010;41:381-5.

58. Zobba R, Anfossi AG, Visco S, Sotgiu F, Dedola C, Pinna Parpaglia ML, et al. Cell tropism and molecular epidemiology of Anaplasma platys-like strains in cats. Ticks Tick Borne Dis. 2015;6:272-80.

\section{Submit your next manuscript to BioMed Central and we will help you at every step:}

- We accept pre-submission inquiries

- Our selector tool helps you to find the most relevant journal

- We provide round the clock customer support

- Convenient online submission

- Thorough peer review

- Inclusion in PubMed and all major indexing services

- Maximum visibility for your research

Submit your manuscript at www.biomedcentral.com/submit
Biomed Central 